AperTO - Archivio Istituzionale Open Access dell'Università di Torino

\title{
Uncertainty in thermal tolerances and climatic debt
}

\section{This is the author's manuscript}

Original Citation:

Availability:

This version is available http://hdl.handle.net/2318/123831

since

Published version:

DOI:10.1038/nclimate1667

Terms of use:

Open Access

Anyone can freely access the full text of works made available as "Open Access". Works made available under a Creative Commons license can be used according to the terms and conditions of said license. Use of all other works requires consent of the right holder (author or publisher) if not exempted from copyright protection by the applicable law. 


\section{(3) \\ UNIVERSITÀ DEGLI STUDI DI TORINO}

This is an author version of the contribution published on:

Questa è la versione dell'autore dell'opera:

Nature Climate Change, 2 : 638-639, 2012, 10.1038/nclimate1668

The definitive version is available at:

La versione definitiva è disponibile alla URL:

http://www.nature.com/nclimate/journal/v2/n9/full/nclimate1668.html 


\section{Estimating uncertainty in species' thermal tolerances and consequences}

Vincent Devictor ${ }^{*}$, Chris van Swaay $^{2}$, Tom Brereton ${ }^{3}$, Lluís Brotons ${ }^{4,5}$, Dan Chamberlain ${ }^{6}$, Janne Heliölä ${ }^{7}$, Sergi Herrando ${ }^{4}$, Romain Julliard ${ }^{8}$, Mikko Kuussaari ${ }^{7}$, Åke Lindström ${ }^{9}$, Jiří Reif ${ }^{10}$, David B. Roy ${ }^{11}$, Oliver Schweiger ${ }^{12}$, Josef Settele ${ }^{12}$, Constantí Stefanescu ${ }^{13}$, Arco Van Strien $^{14}$, Chris Van Turnhout ${ }^{15,16}$, Zdeněk Vermouzek ${ }^{17}$, Michiel WallisDeVries ${ }^{2,18}$, Irma Wynhoff $^{2}$, Frédéric Jiguet ${ }^{8}$

1-CNRS, Institut des Sciences de l'Evolution, France.

2- Dutch Butterfly Conservation, Wageningen, The Netherlands.

3-Butterfly Conservation, UK.

4-Catalan Ornithological Institute, Spain.

5- Centre Tecnològic Forestal de Catalunya, Spain.

6-British Trust for Ornithology, UK.

7-Finnish Environment Institute, Finland.

8-Conservation des Espèces Restauration et Suivi des Populations-MNHN, France.

9- Department of Biology- Lund University, Lund, Sweden.

10- Institute for Environmental Studies, Charles University in Prague, Czech Republic.

11- Centre for Ecology \& Hydrology, UK.

12-UFZ, Helmholtz, Centre for Environmental Research, Dept.of Community Ecology, Halle,

Germany.

13- Museu de Granollers Ciències Naturals, Barcelona, Spain.

14-Statistics Netherlands, The Netherlands.

15-SOVON Dutch Centre for Field Ornithology, The Netherlands.

16-Dept. of Environmental Science and Dept. of Animal Ecology, Institute for Water and Wetland

Research, Radboud University Nijmegen, the Netherlands

17-Czech Society for Ornithology, Czech Republic.

18-Lab of Entomology, Wageningen University, Wageningen, The Netherlands.

*Contact information:

Vincent Devictor: vincent.devictor@univ-montp2.fr 
In their comment, Rodríguez-Sánchez et al. claim that our conclusions on the climatic debt of birds and butterflies [1] are premature because introducing statistical and biological uncertainties in species-specific thermal tolerance (STI, Species Thermal Index) would blur the temporal trend in the Community Thermal Index (CTI). Here, we show why our results are not affected by this uncertainty and further assess the STI uncertainty and its consequences.

An increase in CTI reflects the rate of replacement of individuals belonging to species with low STI by those with higher STI. The actual value of STI for a given species is not what determines the trends in CTI. What really matters is the relative value of the STI among a set of species. The uncertainty of the relative STIs is in fact remarkably low. It is linked to the uncertainty of the spatial distribution of average temperatures over 30 years in Europe, and to the uncertainty of the spatial distribution of common birds and butterflies. The resolution and accuracy of the spatial distribution of temperature in Europe is very high: the difference in long-term average temperature between any two points in space in Europe is known to the nearest $0.1^{\circ} \mathrm{C}$ [2]. Similarly, distribution atlases of European birds and butterflies are among the most accurate available data on animal distribution today. The European atlas of birds integrates 25 years of effort by thousands of skilled field ornithologists and data analysts in more than 40 countries [3]. The butterfly atlas also results from a considerable amount of work and knowledge on species distributions [4]. Therefore, although several sources of uncertainties may affect the exact boundaries of each species distribution, the variation in the relative STIs obtained with these data is very robust to these uncertainties. This uncertainty is also constant through time and similar for most species. The rate of change in CTI should therefore not be affected. Although we agree with Rodríguez-Sánchez et al. that accounting for intraspecific trait variation is crucial, we think that estimating the distribution and magnitude of this variation is even more important [6] and cannot be generated at random.

To illustrate this issue with empirical data, Lindström et al. [5] recently showed that the relative STI is indeed very robust to the change in the data source, the extent of the climatic niche, as well as the time-window considered. They calculated different STI values with different ranges of temperature, extents of species distribution, and with very different sources of data with different sampling efforts, resolutions, or detection probabilities. All these STI values, albeit yielding different uncertainties, were all highly correlated and lead to similar trends in CTI. We further estimated STI uncertainty from two different datasets documenting 
species distributions. We found that this uncertainty is very low (Figure 1a) and does not change the temporal slope in CTI (Figure 1b). This uncertainty is far from what is simulated by Rodríguez-Sánchez et al., who proposed to vary STIs at random by increasing their value by $10 \%$ to $30 \%$ (Note that percentage is meaningless for temperature. Our estimate of STI uncertainty would correspond to $0.068 \%$ ). Such level of uncertainty makes no ecological sense: this would shift the distribution of species at random from several hundred kilometres, which clearly does not correspond to what we know for the species considered. We conclude that such simulations actually do not reflect a relevant aspect of the data used in our study.

Moreover, we acknowledge that the relationship between species fitness and temperature cannot be accounted for by STI only. Most species occur over a range of several ${ }^{\circ} \mathrm{C}$, and changes in temperature within this range is not expected to substantially affect their fate. This is even an underlying assumption of the climatic niche. This is precisely why temporal changes in CTI cannot be directly compared to temporal changes in temperature. The climatic debt calculated in our paper instead uses the ratio between the temporal trend in CTI and the spatial trend in CTI, which accounts for local adaptations, dispersal limitations, species interactions and other factors determining the realised species distributions. This approach has the great advantage to use a ratio between two values estimated with the same basic data and was also proposed to estimate the spatial shift in temperature [7]. The spatial and the temporal slopes of CTI are therefore similarly affected by any bias or uncertainty affecting STIs and can be safely compared. Unfortunately, the authors only briefly mention this crucial step of our reasoning.

Overall, as already discussed in our original paper [1], we acknowledge that the CTI approach has several limitations among which the inability to separate evolutionary adaptation from phenotypic plasticity or true decrease in individual fitness. It is however very different from distribution-based niche modelling methods as it reflects the realized changes in local composition of species assemblages in response to climate change predicatively. Besides, it was recently used successfully with several independent datasets to measure various aspects of biodiversity responses to climate changes for different groups [8], habitats [9] or scales [5]. Also, when applied to species with low dispersal constraint, CTI responded as expected [8]. We therefore think that STI and CTI are indeed very good proxies for climatic niches. All sources of uncertainty can and should be accounted when calculating trends in CTI. But although STI values can be refined with even better ecological data in the future, we think 
that published results on CTI available with current data are unlikely to be flawed by major problems due to STI uncertainty.

\section{Acknowledgements}

We thank Cécile Albert for stimulating comments on the importance of intraspecific variability and its consequences

\section{References}

[1] Devictor, V. et al. Nature Climate Change. 2, 121-124. (2012)

[2] Hijmans, R.J., et al. Intern. Jour. Clim. 25, 1965-1978. (2005)

[3] Hagemeijer, W.J.M. \& Blair, M.J. The EBCC atlas of European breeding birds: their distribution and abundance. London, UK: T. \& A. D. Poyser (1997)

[4] Settele, J. et al. Corrigenda: Settele, J. et al. (2008) BioRisk 2, 33-72 (2009).

[5] Lindström, Å. et al. Ecography, In press, 10.1111/j.1600-0587.2012.07799.x

[6] Albert, C.H. et al. Persp. Plant Ecol. Evol. In press, doi:10.1016/j.ppees.2011.04.003 (2011)

[7] Loarie, S.R. et al. Nature 462, 24-31 (2009).

[8] Godet L., Jaffré M. \& Devictor, V. Biol. Lett. 7, 714-717 (2011)

[9] Kampichler et al. PLoS One 7(4): e35272 (2012) 


\section{Figure 1}

Estimating STI uncertainty and consequences on the temporal trend in CTI. We calculated two sets of STI values estimated with very different datasets. This was possible for Sweden, in which a standardized Breeding Bird Survey (BBS) is running since 1996 and in which the monitored sites ( $\mathrm{n}=716$ fixed sites) are regularly distributed in the country from south to north. From these data, we estimated for each species its "BBS_STI" as the average of each temperature of the monitored site where the species was detected at least once during the period 1996-2008. We compared this BBS_STI with the STI calculated using the Swedish subset of the European Atlas calculated as in [1]. These two estimates of STIs are highly correlated (a). On average, the uncertainty of STI values is $0.068 \%$ (absolute value of the mean of the ratio (Atlas_STI - BBS_STI)/ Atlas_STI). The trend in Swedish CTI (calculated using data from another independent scheme running from 1990) is consequently robust to the change in the STI considered (b).
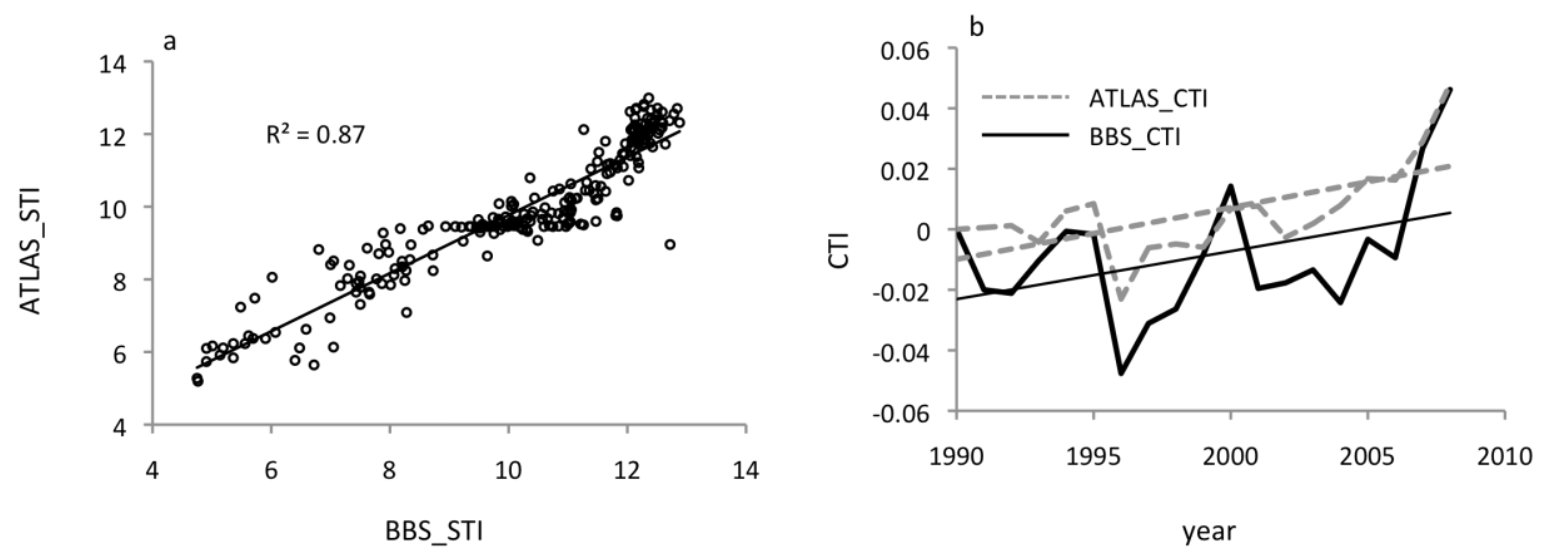